In der Rubrik "Literatur kompakt" referieren und kommentieren diese Experten für Sie die wichtigsten Originalarbeiten aus der internationalen Fachliteratur.

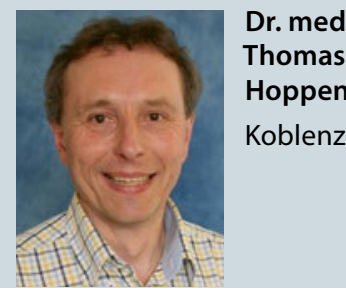

\section{Ein Meilenstein in der Mukoviszidose-Therapie}

\author{
Es tut sich was in der Therapie der zystischen Fibrose: Die Kombination \\ der noch jungen Wirkstoffe Ivacaftor und Lumacaftor zeigte in zwei Phase-III- \\ Studien gute Ergebnisse.
}

D er häufigste für die zystische Fibrose $(\mathrm{CF})$ verantwortliche Gendefekt betrifft das Protein CFTR (Cystic Fibrosis Transmembraneous Regulator). $45 \%$ der Patienten sind homozygote, 25\% komplex heterozygote Träger für die F508del-Mutation, die zu einer falschen Faltung des CFTR führt, wodurch seine Funktion als Chloridkanal im Ionenfluss der Zellmembran stark beeinträchtigt wird.

Ivacaftor ist ein sogenannter CFTRPotenziator, der die Öffnungszeit des

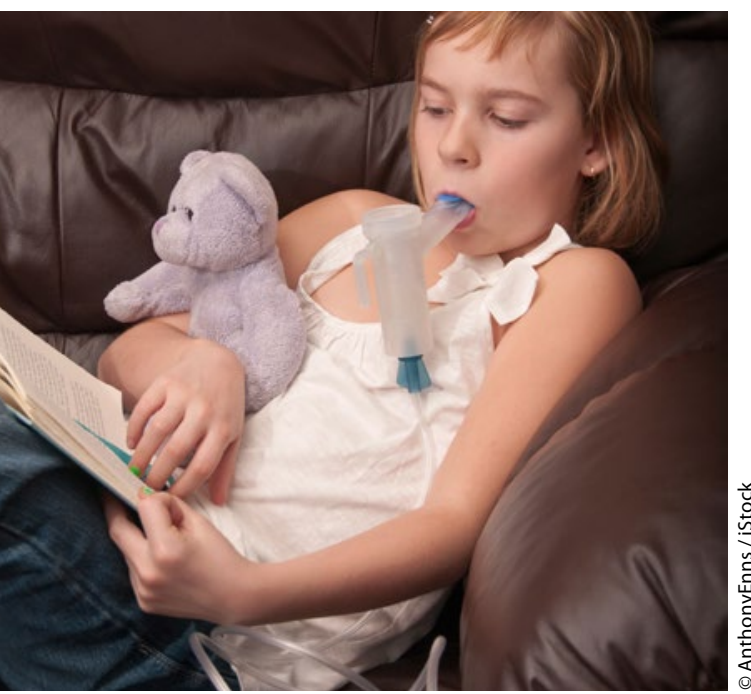

Viele CF-Patienten wünschen sich eine wirksame orale Therapie.
Chloridkanals verlängert. Es hat sich in multizentrischen Studien an CF-Patienten, bei denen ausschließlich die Funktion des CFTR beeinträchtigt war, gegenüber Placebo bewährt. Lumacaftor ist ein sogenannter CFTR-Korrektor, der in vitro die fehlerhafte Prozessierung von CFTR korrigiert, sodass es konsekutiv zu einer Zunahme von CFTR-Protein an der Zelloberfläche der mukösen Drüsen kommt.

Die Kombination beider Substanzen erwies sich in vitro hinsichtlich der Chloridtransportkapazität von CFTR den Einzelsubstanzen überlegen. In zwei randomisierten, doppelblinden und placebokontrollierten Phase-III-Studien sollte nunmehr untersucht werden, ob die Kombination Patienten (älter als 12 Jahre) helfen kann, die homozygot für die F508del-Mutation sind. In beiden Studien erhielten die Patienten über 24 Wochen Lumacaftor $(600 \mathrm{mg} / \mathrm{d}$ oder $2 \times$ $400 \mathrm{mg} / \mathrm{d})$ plus Ivacaftor $(2 \times 250 \mathrm{mg} / \mathrm{d})$ oder Placebo. Primärer Endpunkt war eine Änderung der FEV1.

$\mathrm{Zu}$ Beginn lag die FEV1 bei den 1.108 Patienten im Mittel bei $61 \%$ des Sollwertes. In beiden Studien kam es zu einer signifikanten Verbesserung von 4,3 beziehungsweise $6,7 \%(p<0,001)$. Bei einer gepoolten Analyse zeigte sich, dass die Zahl der pulmonalen Exazerbationen in den Verumgruppen um 30\% bezie- hungsweise 39\% geringer als in den Placebogruppen war. Signifikant niedriger waren auch die Hospitalisationsrate und der Antibiotikaverbrauch. 4,2\% der Patienten in der Verumgruppe brachen die Studie wegen unerwünschter Wirkungen ab, unter Placebo waren es nur $1,2 \%$. Meist handelte es sich aber nur um leichte Atemnot oder Engegefühl in der Brust.

Wainwright CE et al. Lumacaftor-ivacaftor in patients with cystic fibrosis homozygous for Phe508del CFTR. N Engl J Med 2015;373:220-31

\section{Kommentar}

Alle gentherapeutischen Studien zur CF mussten abgebrochen werden, weil die intakte DNA die Zielzellen nicht in ausreichendem Maße erreichte - oder weil die Nebenwirkungen nicht vertretbar waren. Daher will man nun in den intrazellulären CFTRProteintransport eingreifen. Die Kombination von Lumacaftor und Ivacaftor verbesserte in der Studie bei Patienten mit der häufigsten CF-Mutation die Lungenfunktion und reduzierte die Häufigkeit pulmonaler Exazerbationen, den Antibiotikagebrauch und die Hospitalisationsrate.

Viele Fragen bleiben natürlich offen. So waren die Patienten der Studie bereits über 12 Jahre alt. Möglicherweise könnte bei einem früheren Einsatz zum Beispiel eine Infektion mit Pseudomonas verhindert und ein stärkerer Effekt auf die Lungenfunktion erreicht werden.

Auch betrug die Studiendauer "nur" 24 Wochen, während die Therapie in der Praxis ja lebenslang durchgeführt würde. Trotzdem ist die Studie ein Meilenstein für ein mögliches therapeutisches "Targeting“.

Prof.Dr.Dr. Dietrich Reinhard 